\title{
Selection of Patients for Organ Preservation After Chemoradiotherapy: It Is Too Early to Exclude Any Method for Assessment of Response After CRT
}

\author{
Erin D. Kennedy, MD, $\mathrm{PhD}^{1,2}$, and Aman Pooni, MD, $\mathrm{MSc}^{2}$ \\ ${ }^{1}$ Division of General Surgery, Mount Sinai Hospital, Toronto, ON, Canada; ${ }^{2}$ Department of Surgery, University of \\ Toronto, Toronto, ON, Canada
}

\begin{abstract}
"Watch and wait" (W\&W) is a nonstandard, nonoperative approach for patients with locally advanced rectal cancer who have achieved a clinical complete response (cCR) after chemoradiotherapy (CRT), in which surgery is reserved only for patients with development of a local regrowth. The W\&W approach was introduced into clinical practice by Dr. Angelita Habr-Gama in the early 1990s. ${ }^{1}$

To date, several large prospective cohort studies from Brazil, the Netherlands, Denmark, and the UK have reported oncologic outcomes for $\mathrm{W} \& \mathrm{~W}$ similar to those for standard CRT and total mesorectal excision (TME) surgery, reflecting the favorable biology of patients who achieve cCR (Table 1).
\end{abstract}

One of the main challenges with $\mathrm{W} \& \mathrm{~W}$ is accurate identification of patients who achieve cCR after CRT. Table 2 shows an accepted classification system used to assess the level of response after CRT. ${ }^{8}$ This system uses digital rectal exam (DRE), endoscopy, and magnetic resonance imaging (MRI) to classify response after CRT as complete, near complete, or incomplete. ${ }^{9}$

In the original studies reporting W\&W, DRE and endoscopy were used to assess for cCR. More recently, however, MRI has been increasingly used in addition to DRE and endoscopy for this assessment. When MRI is used as part of the evaluation, the tumor regression grade

(C) Society of Surgical Oncology 2020

First Received: 4 March 2020;

Published Online: 12 June 2020

E. D. Kennedy, MD, PhD

e-mail: erin.kennedy@sinaihealth.ca
(TRG) is a critical aspect of the evaluation (Table 3$).{ }^{10}$ The 5-point TRG classification using T2-weighted sequences (T2W) was validated previously by the MERCURY group. ${ }^{10}$

In the current study, Haak et al. ${ }^{11}$ evaluated a modified 3-point TRG (poor, intermediate, good) based on risk of residual tumour using both $\mathrm{T} 2 \mathrm{~W}$ and diffusion-weighted imaging (DWI). For the study, seven expert readers working in different settings each read 62 restaging MRIs and classified them as indicating poor, intermediate, or good responders. The results of the study showed that agreement between the MRI classification based on the interpretation of the reader and the final response outcome (pathology or 2-year follow-up evaluation) was 95-100\% for poor, 76-100\% for intermediate, and 44-67\% for good responders. These results show that when the MRI interpretation denoted a "poor response," this interpretation was generally always correct. The interrater reliability between pairs of the seven readers using weighted kappa ranged from 0.38 to 0.68 and was best for the most experienced readers $(k=0.64-0.68)$.

A main strength of this report is its description of results for seven expert readers in different settings. Consequently, it is more generalizable to the real world setting than a report of only two expert readers in the same setting. Similar results were found by Lee et al., ${ }^{12}$ who compared the 5-point TRG system with a modified 3-point TRG system including DWI. Although interrater agreement between studies should be interpreted cautiously, the results of this study showed that the percentage agreement between two readers (with 3 and 8 years of experience) reading 118 MRIs increased from 38.1-72.9\% using the 3-point TRG, which translated into an interrater reliability 
TABLE 1 Reported outcomes for the watch and wait (W\&W) approach

\begin{tabular}{llclcrrr}
\hline References & $n$ & $\begin{array}{l}\text { Follow-up } \\
\text { Months (range) }\end{array}$ & $\begin{array}{l}\text { cCR } \\
\%(n)\end{array}$ & $\begin{array}{l}\text { LR } \\
\%(n)\end{array}$ & $\begin{array}{l}\text { Surgery for LR } \\
\%(n)\end{array}$ & $\begin{array}{l}\text { Distant METs } \\
\%(n)\end{array}$ & $\begin{array}{l}\text { Overall survival } \\
(\%)\end{array}$ \\
\hline Habr-Gama et al. $^{2}$ & 265 & $57.3(12-156)$ & $26.8^{\mathrm{a}}(71 / 265)$ & $3(2 / 71)$ & $100(2 / 2)$ & $4.2(3 / 71)$ & 100 \\
Habr-Gama et al. $^{3}$ & 183 & $60(12-233)$ & $49(90 / 183)$ & $31(28 / 90)$ & $93(26 / 28)$ & $8.9(8 / 90)$ & 91 \\
Maas et al. $^{4}$ & 192 & $25(4-44)$ & $11(21 / 192)$ & $4.8(1 / 21)$ & $100(1 / 1)$ & $0(0 / 21)$ & 100 \\
Martens et al. $^{5}$ & $\mathrm{NR}$ & $41.1(12-120)$ & $\mathrm{NR}$ & $12.9(11 / 85)$ & $100(11 / 11)$ & $3.5(3 / 85)$ & 96 \\
Appelt et al. $^{6}$ & 51 & $24(15-31)$ & $78(40 / 51)$ & $22.5(9 / 40)$ & $100(9 / 9)$ & $7.5(3 / 40)$ & 100 \\
Renehan et al. $^{7}$ & 259 & $33(19-43)$ & $12(31 / 259)$ & $34(44 / 129)$ & $82(36 / 44)$ & $5.4(7 / 129)$ & 96 \\
\hline
\end{tabular}

$c C R$ clinical complete response, $L R$ local regrowth, $M E T$ metastatic disease

${ }^{a} P a t i e n t s$ with sustained clinical complete response at 1 year

TABLE 2 Classification of response after chemoradiotherapy $(\mathrm{CRT})^{8}$

\begin{tabular}{|c|c|c|c|}
\hline & Complete & Near complete & Incomplete \\
\hline \multirow[t]{2}{*}{ DRE } & Normal & Smooth induration or minor mucosal abnormalities & Palpable tumor \\
\hline & No palpable tumor & & \\
\hline \multirow[t]{4}{*}{ Endoscopy } & White-yellow flat scar & Irregular mucosa & Visible tumor \\
\hline & Telangiectasia & Small mucosal nodules or minor mucosal abnormality & \\
\hline & No ulcer & Superficial ulceration & \\
\hline & No nodularity & Mild persisting erythema of the scar & \\
\hline \multirow[t]{3}{*}{ MRI T2 } & $\begin{array}{l}\text { Only dark T2 signal due to } \\
\text { fibrosis }\end{array}$ & $\begin{array}{l}\text { Mostly dark T2 signal but some remaining } \\
\text { intermediate signal }\end{array}$ & $\begin{array}{l}\text { More intermediate signal than dark T2 } \\
\text { signal }\end{array}$ \\
\hline & AND & AND/OR & AND/OR \\
\hline & No visible lymph nodes & Partial regression of lymph nodes & No regression of lymph nodes \\
\hline MR-DWI & No signal & Significant regression of signal & Insignificant or no regression of signal \\
\hline
\end{tabular}

DRE digital rectal exam, MRI magnetic resonance imaging, $D W I$ diffusion-weighted imaging

TABLE 3 Radiologic MRI classification of tumor regression grade (TRG) ${ }^{9}$

\begin{tabular}{lll}
\hline Tumor regression grade & Degree of response & Description \\
\hline 1 & Complete & No evidence of ever treated tumor \\
2 & Good & Dense fibrosis/mucin, no obvious residual tumor, no visible intermediate signal \\
3 & Moderate & $>50 \%$ fibrosis/mucin and visible intermediate signal \\
4 & Slight & Few areas of fibrosis/mucin, mostly tumor \\
5 & No response & Same appearance and signal as original tumor \\
\hline
\end{tabular}

using a weighted kappa of 0.58 [95\% confidence interval (CI) $0.44-0.72]$ with the 3-point TRG versus 0.34 (95\% CI 0.22-0.46) with the 5-point TRG.

These studies are important because they suggest that a 3-point TRG including DWI has fair interrater reproducibility when two or more expert readers in differing settings report MRI. The 3-point TRG also is a relatively attractive option because it is more consistent with the current clinical classification of response after CRT.

Based on their study results, Haak et al. ${ }^{11}$ suggest that MRI predicted that poor responders should go directly to surgery and that endoscopy can be safely omitted. This is an interesting suggestion, supported by the high agreement between the MRI interpretation for poor responders and the 
final outcome response (95-100\%). However, it is important to note that the proportion of poor responders based on MRI interpretation ranged from 11 to $37 \%$ among the seven readers, indicating that some poor responders were misclassified as intermediate or complete responders. Although the consequence of this misclassification likely is negligible because these patients will undergo DRE and endoscopy, the reported variation in the MRI classification of poor responders among the seven expert readers as well as the overall kappa scores ranging from 0.38 to 0.68 underscore the difficulty interpreting restaging MRI. Furthermore, adopting this strategy for poor responders in jurisdictions with less access to endoscopy may not lead to similar results because these jurisdictions also are likely to have less access to MRI and expert gastrointestinal (GI) radiologists.

Whereas evidence is limited in the literature reporting agreement and reproducibility for endoscopic evaluation and final response outcome, several studies have reported favorable oncologic outcomes with W\&W when only DRE and endoscopy were used to assess for local regrowth. Future studies comparing MRI and endoscopy head-tohead are necessary before the safe omission of endoscopy can be considered. Given this to date, worldwide experience with $\mathrm{W} \& \mathrm{~W}$ has been documented for only 1009 patients. Therefore, it currently would be premature to omit endoscopy or MRI in assessing response after CRT. ${ }^{13}$

\section{DISCLOSURES None.}

\section{REFERENCES}

1. Habr-Gama A. Not taking "no" for an answer. Dis Colon Rectum. 2018;61:8-13.

2. Habr-Gama A, Perez RO, Nadalin W, Sabbaga J, Ribeiro U Jr, Silva e Sousa AH Jr, et al. Operative versus nonoperative treatment for stage 0 distal rectal cancer following chemoradiation therapy: long-term results. Ann Surg. 2004;240:711-7; discussion $7-8$.

3. Habr-Gama A, Gama-Rodrigues J, Sao Juliao GP, Proscurshim I, Sabbagh C, Lynn PB, et al. Local recurrence after complete clinical response and watch and wait in rectal cancer after neoadjuvant chemoradiation: impact of salvage therapy on local disease control. Int J Radiat Oncol Biol Phys. 2014;88:822-8.
4. Maas M, Beets-Tan RG, Lambregts DM, Lammering G, Nelemans PJ, Engelen SM, et al. Wait-and-see policy for clinical complete responders after chemoradiation for rectal cancer. $J$ Clin Oncol. 2011;29:4633-40.

5. Martens MH, Maas M, Heijnen LA, Lambregts DM, Leijtens JW, Stassen LP, et al. Long-term outcome of an organ preservation program after neoadjuvant treatment for rectal cancer. $J$ Natl Cancer Inst. 2016;108:djw171.

6. Appelt AL, Ploen J, Harling H, Jensen FS, Jensen LH, Jorgensen JC, et al. High-dose chemoradiotherapy and watchful waiting for distal rectal cancer: a prospective observational study. Lancet Oncol. 2015;16:919-27.

7. Renehan AG, Malcomson L, Emsley R, Gollins S, Maw A, Myint AS, et al. Watch-and-wait approach versus surgical resection after chemoradiotherapy for patients with rectal cancer (the OnCoRe project): a propensity-score matched cohort analysis. Lancet Oncol. 2016;17:174-83.

8. Smith JJ, Chow OS, Gollub MJ, Nash GM, Temple LK, Weiser MR, et al. Organ preservation in rectal adenocarcinoma: a phase II randomized controlled trial evaluating 3-year disease-free survival in patients with locally advanced rectal cancer treated with chemoradiation plus induction or consolidation chemotherapy, and total mesorectal excision or nonoperative management. BMC Cancer. 2015;15:767.

9. Patel UB, Taylor F, Blomqvist L, George C, Evans H, Tekkis P, et al. Magnetic resonance imaging-detected tumor response for locally advanced rectal cancer predicts survival outcomes: MERCURY experience. J Clin Oncol. 2011;29:3753-60.

10. Taylor FG, Swift RI, Blomqvist L, Brown G. A systematic approach to the interpretation of preoperative staging MRI for rectal cancer. AJR Am J Roentgenol 2008;191:1827-35.

11. Haak HE, Maas M, Lahaye MJ, Boellaard TN, Pizzi AD, Mihl C, et al. Selection of patients for organ preservation after chemoradiotherapy: MRI identifies poor responders who can go straight for surgery. Ann Surg Oncol. 2020. https://doi.org/10. 1245/s10434-020-08334-8.

12. Lee MA, Cho SH, Seo AN, Kim HJ, Shin KM, Kim SH, et al. Modified 3-Point MRI-based tumor regression grade incorporating DWI for locally advanced rectal cancer. AJR Am J Roentgenol. 2017;209:1247-55.

13. van der Valk MJM, Hilling DE, Bastiaannet E, Meershoek-Klein Kranenbarg E, Beets GL, Figueiredo NL, et al. Long-term outcomes of clinical complete responders after neoadjuvant treatment for rectal cancer in the International Watch \& Wait Database (IWWD): an international multicentre registry study. Lancet. 2018;391:2537-45.

Publisher's Note Springer Nature remains neutral with regard to jurisdictional claims in published maps and institutional affiliations. 